\title{
Teacher Identity in Higher Education: A Phenomenological Inquiry ${ }^{1}$
}

\author{
PremPhyak*and Raj Kumar Baral**
}

\begin{abstract}
Teacher identity remains as a major issue of research in the field of teachers' professional development. Understanding the construction of teacher identity is important to fully understand how teachers negotiate their selves with broader institutional power relations and to discuss how teachers invest their agency in building their professional identity. This phenomenological study analyzes the experiencesof six university lecturers with a focus on teacher identity construction in relation to broader institutional culture. This show study shows that university lecturers, who are at the bottom of professional hierarchy, do not receive much institutional support nor are they mentored by their seniors. More strikingly, the study reveals academic identity of the university lecturers are not recognized due to growing culture of partisan politics. This culture has also created sense of fear and unfriendly collegial relations.
\end{abstract}

Keywords: Teacher identity, academic identity, professional development, Tribhuvan University

\section{Introduction}

Teacher identity has received an increased attention in recent studies in the field of teacher professional development (De Costa and Norton, 2017). Keeping teacher identity at the center, studies have focused on the struggles, professional trajectories and sociocultural and political factors affecting teachers' lives and their continual professional development (Lasky, 2005). ${ }^{2}$ However, there are two major issues which are receiving a little attention. On the one hand, most studies are focused on identity of school level teachers, and on the other, there is absence of studies on Nepali teachers' identity in higher education. This study has investigated these issues by looking at the identity construction of teachers in Tribhuvan University. More specifically, this study explores the lived professional experiences of university teachers and analyzes their identity, with a focus on their struggles and negotiations in the existing sociopolitical context of higher education.

\footnotetext{
${ }^{1}$ This article is a part of a Faculty Research under University Grants Commission.

${ }^{2}$ Lasky, S. (2005). A sociocultural approach to understanding teacher identity, agency and professional vulnerability in a context of secondary school reform. Teaching and teacher education, 21(8), 899-916.

* Associate Professor, TU

** Lecturer, TU
} 


\section{Theoretical framework}

This study has drawn on the theories from broader teacher identity literature to discuss the processes and importance of teacher identity in understanding multidimensional aspects of university teachers' identity development. More specifically, we have focused on the personal narratives of lecturers, who are at the bottom of the current teacher hierarchy in the university system. Building on the previous studies on teacher identity (e.g., Dickinson, 2012; Thomas and Beauchamp, 2007), we consider teacher identity as a sociocultural process in that teachers constantly negotiate their own sense of self — both personal and professional - in relation to broader sociopolitical and institutional conditions. While taking teacher identity construction as a socio-interactive phenomenon, this study has explored how university lecturers, focused on Tribhuvan University (TU) build their idea of 'how to be' and 'how to act' as a teacher (Thomas and Beauchamp, 2007) in the current university climate.

This study is informed by the assumption that teacher identity construction is a continual process and shaped by broader politics and structure of an institution. This process involves teachers' personal strategies and negotiation skills with students, colleagues, and senior teachers. More importantly, it encompasses teachers' engagement in understanding and navigating power relation that exists within institutional settings. This power relation can be both structural and discursive. While structural power relation is explicitly linked with prestige, privilege and symbolic capital that different categories of teachers are given, discursive power relation deals with how lectures, also known as 'novice' in the current university teacher hierarchy, see their professional identity in relation to 'senior' or 'expert' teachers. The analysis of discursive power relation pays attention to broader experiences of novice teachers and their sense of imagined professional identity.

Another important aspect of teacher identity construction is the support that teachers are provided with by the institution. Whether or not novice teachers receive appropriate induction and other professional support from the institution and other colleagues, mostly from senior teachers, plays a significant role in newly appointed teachers to find the pathways for professional development. In absence of strong institutional support mechanisms and supportive collegial relationship and mentoring, novice teachers face challenges such as inability to deal with courses and building strong sense of confidence among students.

In line with Varghese et al.'s (2005) framework, we explore and discuss university teachers' identity by drawing on three broad theories which consider teacher identity as part of lived social and professional experiences. These theories include Tajfel's (1978) classic 'social identity theory', Lave and Wegner's (1991) 'community of practice' and Simon's (1995) 'image-text'. While social identity theory allows us to 
understand teachers' social identity that are salient in their professional development, community of practice provides a perspective to look at how novice teachers, lecturers, construct their professional self and membership in interaction with teachers in higher hierarchy - 'Readers' and 'Professors'. In other words, the theory of community of practice helps to understand how lecturers' build their professional relation with their seniors, Readers and Professors, and in what ways the current hierarchy affects in building lecturers' broader professional membership in their institution.

Similarly, the concept of 'image-text' provides insights into understanding the expectations and imaginations of university lecturers'. To put it differently, imagetext supports the idea that teacher identity is not just about what teachers 'are' but also about what teachers 'want to be' and 'want to see'. Together, these theories have helped us understand how teacher identity construction involves both social and professional trajectories of university lecturers.

\section{Research Questions}

The major research question we have addressed are how university teachers construct their professional identity in the current situation of Tribhuvan University. More specifically, we have explored the following questions:

How do university lecturers' perceive abouttheir own teacher identity in the existing context of Tribhuvan University?

What supports have they received for their professional development?

How does the existing sociopolitical culture of Tribhuvan University impacts teachers' identity?

What recommendations do theteachers provide for their professional development as university lecturers?

\section{Rationale for the Study}

Teacher identity construction plays a major role in teacher professional development. Recent studies have shown that it is necessary to understand how teachers 'feel' and 'live' their professional trajectories in order to develop appropriate support mechanism for their professional growth. This understanding requires engaging teachers in telling and critically reflecting on their own personal stories which incorporate professional, social and cognitive aspects of identity construction in a broader institutional setting. 
Although Tribhuvan University recruits and promotes teachers through its Service Commission, what is missing from the current system is how to support teachers, mainly early-career lecturers, for their professional development. There is a general lack of understanding about how university teachers develop their professional identity as university teachers. This study is important as it explores the struggles, emotions and professional trajectories of university lecturers which provide critical insights into understanding what support university teachers need for their professional development.

More importantly, this study provides important policy implications with regard to professional development of university teachers. As we look at the interconnectivity of social and professional identities, this study offers critical insights into understanding teacher professional development as a negotiation of power, identities and sociopolitical dynamics in the current academic system and political environment of Tribhuvan University.

\section{Research Methodology and Data Analysis}

This study adopts a phenomenological research design to collect and analyze data. As a qualitative method, a phenomenological study focuses on the in-depth analysis of teachers' experiences in Tribhuvan University. This phenomenological study pays attention to the lived experiences of participants and draws common themes form the analysis of their experiences. In this study, we purposefully selected six lecturers from University Campus of Tribhuvan University. We selected 4 lecturers from the Faculty of Education and remaining 2 from the Faculty of Humanities and Social Sciences.

The experiences of these teachers are collected through a series of in-depth interviews. More specifically, we interviewed the teachers in both formal and informal settings and observed their interactions with other teachers and students to understand their experiences. We also observed their professional activities such as conference presentations, publications and other involvement that support their professional development. We recorded all the interviews using audio-recorder and field notes. These interviews and fields notes were transcribed and the transcription was code by using analytic and comparative approach to grounded theory which focuses on thematic comparison from participants' experiences. In other words, we organized codes from each narrative under broad themes, related to teacher identity, and interpret them using a comparative approach. This approach helped us understand how each teachers' experiences are unique and critical to draw policy recommendations. Teacher voices, ideology, social identities and their sense of membership in the university teachers' community of practice was kept at the center of the data analysis process. 


\section{Delimitations and Ethical Issues}

By nature, a phenomenological study, like this, includes a small number of participants. In this study, we collected detail narratives of six teachers. Another limitation of this study was that we included the lecturers from only two streamseducation and humanities and social sciences. In a phenomenological study, ethical issues, particularly personal safety is important. We protected the participants' right to anonymity by using their pseudonyms throughout our report. In the beginning of the study, we told the participants that they could withdraw their participation anytime if they felt uncomfortable to be part of the study. In the remainder of the paper, we discuss the major themes that have been drawn from the data. We begin how the university lectures perceive their own identity in the existing university structure:

'Systematically accepted': Sense of professional identity and support in the structure of Tribhuvan University

Regarding their sense of belonging in the existing university system, the participants said that their respective institutions involve them in the professional activities that are 'part of the duty'. Such activities include regular teaching, supervising thesis students and setting and evaluating tests. However, they feel that such regular activities do not much contribute to develop professional identity. Teacher A, for example, reveals that it is not due to the institutional support, but due to his own effort that helps to develop their professional identity. He says that "students made me what I am." He further says:

Frankly speaking, there is a little or no institutional support for my professional development. Except for a few guest lecture sessions, I don't remember my department sending me to attend any refresher courses or seminars. There is no such sponsorship. There is no additional incentive, reward or acknowledgment of good works. Else, in these ten years of service, I would have had the opportunity to recall a day when my institutional head called and congratulated me for at least ONE good work I did. No; there is nothing to recall. If we work hard with our own conscience, maybe professional development will come about. There is ZERO initiative from the department.

As Teacher A has experienced, other teachers have also said that they hardly receive professional development opportunities from their institution. More importantly, the leadership rarely recognizes their good work. In this regard, teacher D says:

I don't have any exciting memory to recall from among my colleagues, except for a few of my classmates and colleagues, who 
always gave me their hands in need. But my leadership never made me feel anything warm. The only memorable anecdotes I have are connected with my students. I remember students saying how, due to my personal love and care, they resolved their depression and withdrew their decision to quit study, and held themselves back until they completed their master's degree. I remember them saying they are in writing and journalistic field with inspirations from me. Many of my students have become a part of joys and sorrows. They were with me during my family tragedies and my family celebrations. They still are. With few or no relative living near to me in Kathmandu, I turn to my students whenever I need close people. And they have always presented themselves. This makes me think, I am very much with my students and they with me.

The teachers also feel that the existing hierarchical structure is affecting their professional development. They feel that junior faculty members do not receive much support from their institutional leadership. For example, teacher A reveals:

But my department perhaps has no information about this, or at least is indifferent to my overwhelming popularity among my students. I am very junior faculty, and the number of recommendation letters I write for students whenever they are applying abroad makes me think they confide in me and have faith in me. Yet, I am Hemingway's protagonist in a lonely sea. This much is for sure.

Regarding the institutional support, Teacher E says:

In case of opportunities, self goes first. If it is economically or anyway beneficial then seniors go first. And if large number or everybody can get involved then juniors can go as well. In case of institutional support, sometimes ICT related trainings are held for professional development. When I first entered here in semester system, we were given training on how to teach through PowerPoint. But there's not as much support as there should be.

Teacher $\mathrm{C}$ has a similar perspective:

Years back I did ICT related training. Other than that, training for teachers and motivations, I haven't got any. Even when journals are to be published, they look for their own people or who are close to them. So, whatever you do, you do it on your own. If you can speak up and claim for your article to be published then something can happen but if you stay quite then nothing is going to happen. But from the side of institution, I don't think it has done anything for its teachers. Instead when people themselves want to do something 
good, they are demotivated, difficulty is created in front of them, pulling of legs begin. But not everyone is like that. Few teachers have encouraged me at times and that keeps me motivated.

One lecturer, Teacher $\mathrm{C}$, who had taught for 10 years in an out-side valley campus feels that there is lack of institutional support from his professional development. Except for regular leaves, there is lack of support plans for further professional development of faculty members. He tells his experiences as follows:

In case of professional development, organization provides holiday to do MPhil and PhD. Besides that, for regular teaching like inservice teaching and extra motivations and classes, we haven't had any assistance from the university. During my ten years of teaching, while I stayed in hostel, once I participated in Course Destination program. Since then I haven't had any opportunity. And in that also, only TA and DA was provided, nothing else. Besides that, research training, workshop training and every other knowledgeable programs organized by university are very few. Even in that, one can participate only if one has personal influence and contact. There's no HRD [Human Resource Department] department in the university to see that field. And now I've heard that University Grants Commission supports some proposals for such programs. But as there is HRM [Human Resource Management] department in other organizations, we don't have it here in TU. After candidates are appointed, HRM department looks after creating programs for developing, motivating and uplifting them. There's nothing like that here.

Teacher $\mathrm{C}$ focuses on the need for establishing a human resource development department to support university teachers' professional development efforts. His experience tells that except for participating in a 'course dissemination' program, he has not received any opportunity for in-service professional development. $\mathrm{He}$ recounts:

Whatever is done, is done by yourself, through your own influence. People care very less about each other. Intimacy is low. Employees of one department do not know the employees of the other departments. University has never organized any program so that we could get to know each other.

Furthermore, he claims that 'personal influence and contact' is necessary to participate in professional development activities. 
Invisible academic and professional identity: Factors affecting identity construction Teacher identity is shaped by sociocultural and institutional landscape. The participants in this study see that the new institutional culture, which is influenced by national political context, has significantly contributed to shape their professional identities. One of the participants (Teacher D), who has taught for more than 10 years in Tribhuvan University, shares that it has been difficult for teachers to survive by doing academic work only. For him, in addition to academic identity is valued less than the 'membership of political parties'. He claims that:

There's very slim chance of survival in university through only a pure academic exercise. If you cannot create your clear identity through the affiliation of any political ideology then it won't be easy for you. Before evaluating your performance, they look for which party you belong to. If you are not able to identify yourself that way, no one will recognize you, no one will protect you. You become like an eklobrihaspati. So, no one will appreciate your academic life. If you think of existing independently by doing only academic work, that will create difficulty.

Participant D's metaphor of 'aklo Brihaspati' indicates that teachers who do not have affiliation with partisan politics hardly receive institutional support for professional development. Since university institutions are run on the basis of 'bhagbanda' (share among teachers' groups affiliated with political parties), teachers who are not open to any groups become 'helpless' in many ways. In this regard, he reveals that

Yes, this is the culture of this university. There is scarcity of capable people in the university and those who cannot compete and cannot make academic contributions are abundant. So, those people take the shelter of a party to exist, and have strong political power behind them. And the person who does not follow the culture of factionalism has to get frustrated and flee despite he/she is capable.

He further states that,

Only with academic identity, it is difficult to grow, survive and thrive, and to have satisfaction. If you have capacity and have made contributions then you must be given a role. While giving you that role, you get public concern on who you are. And as the positions are already divided according to parties, you cannot be given a position when you don't have a clear political identity, even if you are an expert. 
His observation indicates that 'academic and professional identities are secondary' and teachers are primarily identified by 'their affiliation to teachers' groups, who they are close to and who they vote." One critical issue that emerged from the narrative of the participants in this study is that teachers' identity, based on their political affiliation, begins from the hiring stage. Teachers, even part-time, should belong to political parties and recommended by teachers' groups in the university to ensure the 'authenticity of their affiliation'. Teacher E told that once teachers are first known by their 'political identity', their academic identity remains 'invisible' and 'secondary' throughout their academic career. She shares his story as follows:

The concept of political factionalism was there when I entered here. Teachers from one group padlocked our department when part-time teachers were hired. They said that the selection was not according to their demand. In the time of promoting parttime teachers to contract, it is very difficult for our Head. He did not know which party the part-time teachers belong to. He suggested that the part-time teachers should get support of each factions of teachers. Head sir was saying for the good cause. Finally, each of them received support from different factions and promoted to contract teachers. From that point, those teachers' identity has changed. Now they are known as a member of political factions. They are all good teachers...but it's unfortunate their academic identity is secondary.

Teacher's professional identity is shaped by multiple factors. One of the primary factors include salary. In this study, teachers reveal that the existing salary is not sufficient for them to carry out research and other professional development activities. Teacher F, for example, states that

University has not been able to utilize people's potentialities at maximum level. Less work. Less payment. Service and facility provided by Nepal Government is very low. To be satisfied on this, economically, is challenging. The situation of salary is like people will want to leave the profession in two days.

Like Teacher F, teachers in this study are not happy with salary. Since salary is 'very low', as Teacher F says, university teachers 'want to leave the profession in two days'. More importantly, teachers in this study are critical about unsystematic promotion system. Teachers believe in 'capacity' rather than the promotion. Teacher E, for example, asserts that 'there's no difference between a lecture and a professor. If one can build capacity then lecture is also enough." Teacher E recounts,

There is no much difference because a professor and a reader. Because promotion is done through sequence and setting. If my articles are evaluated by someone who favors me and supports me, then I can easily become a reader and a professor. But if he does not 
support me and is biased to me then wherever my journal may be published, he won't favor me. I am not promoted.

Like Teacher E, other participants in this study also reveal the emerging and influencing 'culture of factionalism' in Tribhuvan University. Since teachers receive support based on their loyalty to 'factions', in terms of partisan politics, the participants in this study feel 'alienated'. Teacher E feels that the institution where his individual efforts are even 'restricted' by the institution. For him, 'when color does not match', the leadership creates problems for individuals as well. 'Color' here refers to 'political color' of teachers.

\section{Sense of fear and hierarchical structure of the university}

Tribhuvan University has a strong hierarchical structure that gives more importance to the year of teaching experiences than teachers' academic strengths and research. Professors and Readers enjoy more privilege in receiving institutional support than lecturers. Participants in this study agree that the existing structure and 'hierarchical system' in the university is not supportive for lectures. Indeed, Teacher D feels that there is 'a sense of fear' among teachers due to the hierarchical structure of the university.

It's not that our seniors do not mentor us. Our department is small and they do support us. But even when they will, they have not been able to support us all the time. They themselves are marginalized.

The teachers in this university also expressed sense of fear in the existing culture of factionalism and hierarchy. One important phenomenon that emerges from the narratives of the teachers is 'aaphnomanche' culture. In this regard, Teacher B shares his experience as follows:

Unless anyone considers you mine, you cannot enter anywhere [in the university]. All doors are closed. Someone who is less competent than you goes ahead because of membership of factions. I am really frustrated seeing this situation. When I became open as a member of one faction, everyone's behavior towards me has totally changed. Now, I feel safe. If I am in any problem, there's my faction behind me. So, here, instead of worrying about academic works and professional development, I have to fear about whether I will be victim of any other party. We have to focus on which party is dominating which sector, and where I can get the opportunity. This is similar to a kind of fear. So, while entering into class also, there's similar kind of situation. Politics among teachers is reflected among students as well. Once, a teacher in our department was replaced with the influence of strong political power. And that 
teacher was not even pre-informed. So, we raised our voice against such humiliation. Then they made a plan. Before also few problems were seen in his class. So, they thought that when students themselves will reject the teacher, they will bring their member in that place. But the students did not reject the teacher. Such plans are also made.

The hierarchical structure is also affecting in teachers' identity. Teachers in this study consistently argue that there is 'unsaid discrimination' between 'senior' and 'junior' teachers. Teacher $\mathrm{C}$, for example, reveals that

There are divisions like lecturer, part-time teacher, associate professor and professor. Routine is made according to the convenience of senior professors, according to their time. And part-time teachers are compelled to come at any time that department wants. I also began that way. I had to come at morning, afternoon, whenever they wanted me to come. But not all teachers are like that. Some are there to encourage as well. But there's gap between seniors and juniors.

Similarly, Teacher $\mathrm{C}$ reveals that

There's gap between senior and junior. In any committee, only seniors are kept, there's no place for juniors. We as juniors do not even get to know what kind of committee that is and how it functions. People think about their future. And seniors are there in the committee of promotion and everywhere. If they speak against the seniors, they are finished. Those people, who are close to them, who obey and work for them are favoured by the seniors. So, it's difficult to challenge. Everything is connected to seniors.

In the same line, Teacher D says:

Yes. And it's much difficult. Even in routine allocation, there is hierarchical influence. Like I already said, the convenience of seniors is acknowledged while preparing routine. But even if juniors have problem, they must come at any time they are called. And, also, people don't speak. There's trend that whatever senior says must be done. And the one who speaks is considered to be disrespectful.

As Teacher D has revealed, the existing hierarchical culture impacts in daily activities of lecturers. Since the allocation of time and classes is also influenced by the hierarchy among faculty members, junior faculty are forced to follow what their seniors say. More importantly, this hierarchical culture has silenced the voices of the 
juniors. Junior faculty members 'don't speak' even if they would like to share their discomfort because speaking up is considered 'disrespectful' for seniors.

The experiences of teachers who are the bottom of professional hierarchy as determined by Tribhuvan University show that there is lack of institutional support for professional development of faculty members. Teachers work hard to explore their own professional opportunities. The teachers' experiences also imply that the existing hierarchical structure is less supportive for university teachers' professional development. Teachers' sense of fear is a critical issue that emerges from the existing hierarchical structure of the university. More importantly, the growing influence of political factions has invisibilized their professional identity and given focus on the political identity.

\section{Findings and Conclusion}

According to the research, since academic university teachers, particularly lecturers, are not provided many opportunities for their professional development, they have strong sense of demotivation and fear.Academic identity remains in crisis as teachers are evaluated in terms of their political identity.University lecturers have strong sense of fear in the existing hierarchical structure of the university system.Institutional support for professional development of teachers hardly exists in the university. Lecturers wish to see university as an ideal place for academic practice and the responses of the respondents reveal that different appointments on the basis of political groupings have negative affects.

The research concludes that lack of motivational factors influence professional development of the lecturers and their evaluation vis-à-vis political identity hinders their professional life. Existing hierarchy in university affects one's development ultimately influencing professional identity of the individual, therefore unless a lecturer is supported by his/her institute, s/he has to face problems in career development. Institutional negligence makes one frustrated. The recent scenario reveals that the aura of university is declining gradually, therefore, to maintain its height, we have to think to make it a temple of knowledge, not a place of political foul play. Finally, appointments should be made not on the basis of political affiliation but on the basis of their expertise. 


\section{References}

Cheng, X. (2016). A Narrative Inquiry of Identity Formation of EFL University Teachers, Journal of Education and Training Studies, 4(5), 1-7.

De Costa, P. I. and Norton, B. (2017) Introduction: Identity, Transdisciplinarity, and the Good Language Teacher. The Modern Language Journal, 101, 3-14.

Dickinson, S. J. (2012). A narrative inquiry about teacher identity construction: Preservice teachers share their stories, $\mathrm{Ph}$. D. dissertation. University of Missouri-Columbia.

Lave, J., \& Wenger, E. (1991). Situated learning: Legitimate peripheral participation.Cambridge,England: Cambridge University Press.

Simon, R. I. (1995). Face to face with alterity: Postmodern Jewish identity and the eros ofpedagogy. In J. Gallop (Ed.), Pedagogy: The question of impersonation (pp. 90-105).Bloomington: Indiana University Press.

Tajfel, H. (1978). Differentiation between social groups: Studies in the social psychology ofintergroup relations. London: Academic.

Thomas, L., \& Beauchamp, C. (2007). Learning to live well as teachers in a changing world: Insights into developing a professional identity in teacher education. The Journal of Educational Thought, 41(3), 229-243.

Varghese, M., Morgan, B., Johnston, B., \& Johnson, K.A. (2005). Theorizing languageteacher identity:Three perspectives and beyond. Journal of Language,Identity \& Education, 4, 21-44. 